\title{
AS TECNOLOGIAS DA INFORMAÇÃO E DA COMUNICAÇÃ̃ COMO MEDIAÇÃO PEDAGÓGICA NO CURSO DE PEDAGOGIA
}

\author{
Valéria Alves de OLIVEIRA ${ }^{1}$ \\ Herivelto MOREIRA ${ }^{2}$
}

RESUMO: O artigo apresenta parte dos resultados da dissertação de Mestrado realizada no Programa de Pós-Graduação em Tecnologia da UTFPR, cujo objetivo foi analisar como os professores do Curso de Pedagogia de uma universidade particular do Estado do Rio Grande do Sul - Brasil utilizavam as Tecnologias da Informação e Comunicação (TICs) em suas práticas pedagógicas para a formação de futuros professores. A revisão da literatura para o estudo foi elaborada a partir de vários autores nacionais e internacionais. Para esse artigo foi feito um recorte da revisão literatura, abordando mais especificamente a importância da utilização das TICs para a formação de professores e a inovação pedagógica com o uso das tecnologias para a construção do saber. A abordagem utilizada foi a pesquisa qualitativa de natureza interpretativa. A amostra constitui-se de treze professores de Curso de Pedagogia. A técnica de coleta de dados foi a entrevista semi-estruturada. Para a finalidade deste artigo será apresentado apenas duas das categorias discutidas na dissertação. Os principais resultados mostram que as TICs são utilizadas para transmissão de informação e não como um recurso para auxiliar no desenvolvimento do processo de ensino-aprendizagem e grande parte dos professores entrevistados possui dificuldades para utilizar recursos tecnológicos na prática pedagógica

PALAVRAS-CHAVE: Educação. Tecnologia da informação e comunicação. Aprendizagem. Mediação pedagógica. Inovação pedagógica.

\section{Introdução}

A utilização das Tecnologias da Informação e Comunicação (TICs) em diversas áreas do conhecimento tem provocado mudanças em vários espaços sociais e privados, inclusive na educação. A presença das tecnologias na sociedade demanda das instituições de ensino e professores novas atitudes em relação ao processo de ensinoaprendizagem, principalmente no ensino superior, e em especial no Curso de Pedagogia, pelo fato de formar futuros professores. As tecnologias, como recurso pedagógico, oferecem inúmeras possibilidades para a prática docente, mas é preciso reconhecê-la como uma nova forma de ensinar e aprender, aprimorando os métodos tradicionais de

\footnotetext{
${ }^{1}$ Mestre em Tecnologia. UTFPR - Universidade Tecnológica Federal do Paraná - Programa de PósGraduação em Tecnologia. Curitiba - PR - Brasil. 80230-901 - valalvesdeoliveira@ hotmail.com.

${ }^{2}$ Professor Doutor do Programa de Pós-Graduação em Tecnologia. UTFPR - Universidade Tecnológica Federal do Paraná. Curitiba - PR - Brasil. 80230-901 - herivelto.moreira51@gmail.com.
} 
ensino. O desafio é fazer com que esses recursos provoquem melhorias na qualidade do ensino e não se tornem apenas ferramentas de transmissão de informações.

As tecnologias podem melhorar e inovar o processo de ensino- aprendizagem, trazendo novas possibilidades, recursos dinâmicos e interessantes, que despertem a atenção, a curiosidade e o interesse pelo conhecimento. Mas há também a necessidade de se analisar quais são os recursos disponibilizados e como eles poderão contribuir para se alcançar os objetivos esperados. A simples presença das TICs na prática pedagógica não vai promover mudanças no ensino, mas sim a maneira que o professor utiliza e integra esses recursos é que poderá provocar inovações, contribuindo assim para o desenvolvimento do processo de ensino-aprendizagem.

De acordo com Behrens (2000, p.103), “[...] a inovação não está restrita ao uso da tecnologia, mas também a maneira como o professor vai se apropriar desses recursos para criar projetos metodológicos que superem a reprodução de conhecimento e levem a produção do conhecimento". A tecnologia por si só não vai provocar melhorias no contexto educacional, ela será somente eficaz na mediação e na construção do conhecimento, quando utilizada além de uma simples transmissão de informação.

Mishra e Koehler (2006) discutem a integração de tecnologias na prática pedagógica dos professores. Os autores argumentam que a atividade docente exige um saber que integre a tecnologia na sua prática. Nesse sentido, faz-se necessário avaliar, analisar e selecionar conteúdos e metodologias a serem trabalhadas com as TICs, a fim de proporcionar melhorias na educação.

Se a integração de tecnologias na educação está ligada a prática do professor, é necessário que haja uma formação direcionada para a utilização das TICs como recurso pedagógico na sua prática docente. No entanto, esse processo de formação não poder ser visar apenas à capacitação técnica e sim uma formação que o capacite para; usar as tecnologias para a inovação pedagógica.

Portanto, o objetivo deste artigo é apresentar parte dos resultados da dissertação de Mestrado realizada no Programa de Pós-Graduação em Tecnologia da UTFPR, cujo objetivo foi analisar como os professores do Curso de Pedagogia de uma universidade particular do Estado do Rio Grande do Sul - Brasil utilizavam as Tecnologias da Informação e Comunicação (TICs) em suas práticas pedagógicas para a formação de futuros professores. 


\section{Revisão da literatura}

A instituição de ensino deve ser vista, ao mesmo tempo, como um ambiente de transmissão de saber e questionadora desse mesmo saber e, ainda como um ambiente formador de novos saberes; deve ser também uma instituição instigadora, onde a capacidade de imaginar, criar e praticar seja estimulada (VASCONCELOS, 2009). Assim, cria-se um espaço para a integração e para a interlocução entre vários sujeitos em busca de novos saberes. Tudo isso para que o saber possa ser construído em conjunto com processos de informações, comunicação, interação e mediação das ações. A tecnologia pode se tornar uma grande aliada, pois gera novas maneiras de pensar e representa um novo ambiente na formação de alunos. Diante desse novo cenário educacional, “[...] criou-se uma nova demanda para as aulas universitárias: o uso das tecnologias de informação e comunicação (TICs) em sua realização.” (MASETTO, 2011, p.612).

As TICs são recursos que possibilitam através de metodologias inovadoras novas formas de ensinar e aprender, uma vez que o trabalho docente demanda muitos tipos de conhecimentos para além daquele limitado ao conhecimento científico de suas disciplinas e, de técnicas para transmiti-los, pois ensinar é uma atividade complexa.

Em relação aos conhecimentos docentes, Shulman (1986) desenvolveu um conjunto de conhecimentos para a profissão docente, entre eles estão os saberes relacionados ao conteúdo e os saberes relacionados ao processo de ensinar. O autor classifica os conhecimentos da seguinte maneira: Conhecimento do conteúdo (Content knowledge); conhecimento pedagógico geral (general pedagogical knowledge); Conhecimento Pedagógico do Conteúdo (Pedagogical Content knowledge); conhecimento curricular (curriculun knowledge); conhecimento dos alunos e suas características; (knowledge of learners and their characteristics), conhecimento dos contextos educativos (knowledge of educational contexts) e conhecimento dos fins, propósitos e valores educacionais (Knowledge of educational ends, purposes and values).

Mishra e Koehler (2006) baseados na classificação de Shulman (1986), especificamente sobre conhecimento pedagógico do conteúdo desenvolveram o modelo de interdependência do conhecimento docente. Esse modelo é constituído pelo Conhecimento Pedagógico (PK)- conhecimento sobre processos, práticas e métodos de ensino, que engloba as questões de aprendizagem, planejamento de aulas, estratégias, 
objetivos educacionais, entre outros. O Conhecimento do Conteúdo (CK)conhecimento sobre o assunto a ser ensinado e mais o Conhecimento Tecnológico (TK)o conhecimento que engloba as tecnologias tradicionais (livro, giz, quadro-negro, etc.) e as tecnologias digitais ou tecnologias da informação e comunicação (computadores, vídeos, software, etc.).

Os autores argumentam que a combinação desses três tipos fundamentais de conhecimentos resulta quatro tipos de conhecimentos: da combinação entre o Conhecimento Pedagógico e o Conhecimento do Conteúdo resulta o Conhecimento Pedagógico do Conteúdo (PCK- Pedagogical contente Knowledge), envolve o conhecimento de estratégias de ensino que incorporam metodologias adequadas para enfrentar as dificuldades do aluno. Também inclui o conhecimento do que os alunos trazem para a situação de aprendizagem, ou seja, o conhecimento prévio dos alunos. Da combinação entre Conhecimento Pedagógico com o Conhecimento Tecnológico resulta o Conhecimento Tecnológico e Pedagógico (TPK- Technological pedagogical Knowledge), a compreensão de como usar determinados recursos tecnológicos com estratégias pedagógicas que favoreça o ensino. Da interseção entre Conhecimento de Conteúdo e o Conhecimento Tecnológico, resulta o Conhecimento Tecnológico do Conteúdo Conteúdo (TCK-Techonological Content Knowledge), o conhecimento sobre a maneira pela qual a tecnologia e o conteúdo estão relacionados. Da combinação entre as três categorias fundamentais do conhecimento resulta o Conhecimento Tecnológico Pedagógico do Conteúdo (TPCK- Technological Pedagogical Content Knowledge.

Esse conhecimento enfatiza as relações existentes entre tecnologia pedagogia e conteúdo. Envolve o ensino de conteúdos utilizando estratégias, métodos, que usam as tecnologias de maneira eficiente para ensinar o conteúdo de forma diferenciada, considerando como as TICs podem contribuir para o ensino. O TPCK ajuda a identificar componentes importantes do conhecimento dos professores que são relevantes para a integração cuidadosa da tecnologia na educação. $\mathrm{O}$ objetivo principal desse conhecimento $(T P C K)$ é a conexão dos conhecimentos do conteúdo, pedagógico e tecnológico que formam a base para sua estruturação.

O modelo desenvolvido por Mishra e Koeller (2006) poderá auxiliar na elaboração de cursos de formação docente que abordem o conhecimento tecnológico de forma integrada ao conteúdo das diferentes disciplinas e não de forma isolada como acontece atualmente. O Conhecimento Tecnológico Pedagógico do Conteúdo - TPACK gera melhores resultados quando o professor sabe como usar a tecnologia e como esta 
pode representar um impacto sobre a compreensão do aluno a respeito dos conteúdos abordados, pois integrar as TICs no ensino para inovar a prática pedagógica de modo que contribua com o processo de ensino-aprendizagem é uma tarefa complexa, uma vez que exige dos professores de qualquer nível de ensino comprometimento, esforço, dedicação e aprendizado.

Para Brito e Purificação (2006, p.37), o conceito de inovação no ensino, “[...] está envolvido a utilização de novas tecnologias em sala de aula, o que implicará novos projetos fundamentados em concepções de ensinar e aprender diferentes das propostas já existentes". A inovação no campo educacional com uso de tecnologias surge na tentativa de proporcionar aos alunos situações de aprendizagem inovadoras. Na visão de Carbonell (2002), a inovação é o meio de aprimorar a prática pedagógica, podendo modificá-la e melhorá-la construindo saberes a partir do contexto atual. Para o autor, o conceito de inovação é:

[...], introduzir, em uma linha renovadora, novos projetos e programas, materiais curriculares, estratégias de ensino e aprendizagem, modelos didáticos e outras formas de organizar e gerir o currículo, a escola e a dinâmica da classe. (CARBONELL, 2002, p.19).

Pode-se compreender a inovação no contexto educacional como algo capaz de promover por meio da ação docente consciente mudanças na mediação pedagógica com o intuito de renovar as estratégias tradicionais de ensino em prol da construção do saber.

A perspectiva de trabalhar com as TICs no ensino superior modifica o papel docente de mero transmissor e coloca o aluno como sujeito de aprendizagem, fazendo com que o professor reveja suas competências pedagógicas. Quando se trata de utilizar as tecnologias para inovar o trabalho pedagógico mais importante que dominar o uso desses recursos, é preparar os alunos para usar as tecnologias de forma crítica, uma vez que estas dão acesso a uma quantidade substancial de informações, o que torna necessário analisar e selecionar os conteúdos para potencializar o processo de ensinoaprendizagem.

Não se trata de eliminar as metodologias tradicionais, e sim repensar as atividades pedagógicas existentes para explorar quais serão as mudanças relevantes que poderão ser utilizadas com o auxílio de recursos tecnológicos que possam inovar a prática docente e, consequentemente, melhorar a aprendizagem dos alunos. Ao professor cabe analisar o que é pertinente ou não no uso das tecnologias para fins 
pedagógicos, fazendo uma análise crítica do que realmente é adequado para o desenvolvimento de suas aulas e atividades.

As tecnologias não surgiram no intuito de substituir o professor, ao contrário, chegaram como um recurso para auxiliar e aperfeiçoar o processo educacional. Em relação a essa questão, Haydt (2003, p.280) argumenta que “[...] na escola, o computador deve ser usado não como um substituto do professor, mas como um recurso auxiliar de que ele dispõe para facilitar o desenvolvimento do trabalho pedagógico [...]”. Portanto, cabe aos profissionais da educação explorar os caminhos, possibilidades e limitações do uso das TICs no ensino, uma vez que deste modo estarão formando futuros profissionais da educação capazes de atuar de maneira mais inovadora na sua futura prática docente.

\section{Metodologia e procedimentos}

A pesquisa foi qualitativa de natureza interpretativa. De acordo com Moreira e Caleffe (2006, p.73), esse tipo de pesquisa “[...] explora as características dos indivíduos e cenários que não podem ser facilmente descritos numericamente”. A pesquisa qualitativa oferece condições para que se possa investigar o fenômeno com base nas percepções dos indivíduos envolvidos nas atividades que serão investigadas.

A técnica utilizada para a coleta dos dados foi a entrevista individual semiestruturada. De acordo com Moreira e Caleffe (2006, p.169), ao usar esse tipo de entrevista "[...] é possível exercer um certo tipo de controle sobre a conversação, embora se permita ao entrevistado alguma liberdade". O protocolo de entrevista originou-se da revisão de literatura e da análise documental. O protocolo constitui-se de cinco blocos: I. Formação docente; II. Saberes docentes; III. Percepção das tecnologias; IV. Tecnologia e aprendizagem; V. Instituição. Foram realizadas duas entrevistas-piloto para verificar o entendimento dos participantes do estudo sobre o teor das perguntas elaboradas no protocolo. Após a análise das entrevistas-piloto, foi feita uma alteração, acrescentando-se duas perguntas no protocolo: uma sobre o determinismo tecnológico e outra referente à disciplina "Educação e Tecnologias" que consta no currículo do curso.

A seleção da amostra dos entrevistados seguiu a estratégia bola-de-neve, pois como afirmam Moreira e Caleffe (2006, p.178) “[...] essa é uma abordagem para localizar informantes-chave que possuam informações ricas ou então para localizar casos críticos". Desta forma, os participantes inicialmente entrevistados indicaram outros colegas que poderiam trazer maior colaboração para a temática do estudo e assim 
sucessivamente. Nesta abordagem, não se delimita o tamanho da amostra a priori, pois as entrevistas são encerradas quando se identifica o que Bogdan e Biklen (1994) chamam de saturação de dados, ou seja, no momento em que as informações coletadas começam a se repetir.

A amostra final constituiu-se de treze professores (de um total de vinte e dois professores) do curso de Pedagogia de uma universidade privada localizada no Estado do Rio Grande do Sul, sendo (4) professores e (9) professoras, com idades entre 28 e 49 anos, sendo a média de idade de 40 anos. Quanto ao estágio na carreira de docência de ensino superior, um (1) professor está em fase inicial da carreira (menos de 6 anos), oito professores estão no estágio intermediário ( 7 a 12 anos) e três professores encontram-se no estágio avançado da carreira (mais de treze anos). Dos treze professores entrevistados, dez possuem experiência na Educação básica e os demais iniciaram a carreira docente no ensino superior. Apenas quatro professores possuem graduação em Pedagogia, os demais são formados em Filosofia, Psicologia, Desenho e Plástica, Ciências Biológicas, Letras e Matemática. Todos os professores possuem pósgraduação, sendo que doze em nível de mestrado e um em nível de doutorado. A maioria dos professores tem uma jornada de trabalho de quarenta horas semanais e possuem, em média, 10,4 anos de magistério no ensino superior.

Para a coleta de dados, foi apresentada uma carta para o Diretor da Instituição a fim de solicitar a permissão para a condução do estudo, que foi concedida. No momento da entrevista, os professores assinaram um termo de consentimento informado sobre a utilização dos dados em futuras publicações, garantindo o anonimato e o sigilo das respostas. As entrevistas foram conduzidas na própria instituição dos participantes e o tempo médio de duração foi de 72 minutos. Todas as entrevistas foram gravadas e transcritas literalmente e depois enviadas aos entrevistados para a validação dos dados.

\section{Análise e interpretação dos dados}

Para analisar os dados foi utilizado o método comparativo constante de análise de dados qualitativos, porque possibilita a associação e combinação de categorias indutivamente com uma comparação simultânea de todas as unidades de significado obtidas (GLASER; STRAUSS, 1967, apud MOREIRA; CALEFE, 2006, p.8). A análise foi realizada por meio do software MAXQDA10.

As fases da análise foram: (1) a exploração preliminar dos dados por intermédio da leitura de todas as transcrições das entrevistas e registro de memorandos e ideias; (2) 
a codificação dos dados no sistema de códigos do software; (3) unitização dos códigos e o uso dos códigos para desenvolver categorias preliminares de opiniões semelhantes; (4) conectar e inter-relacionar as categorias preliminares; (5) a definição das categorias finais; (6) e a construção das narrativas compostas da interpretação e discussão das categorias. A validade dos resultados foi garantida pela triangulação de diferentes fontes de informação, verificação pelos entrevistados, descrições ricas e profundas das opiniões dos entrevistados e do orientador acadêmico.

Cinco categorias emergiram dos dados, mas para efeitos deste artigo será apresentada apenas duas das cinco categorias discutidas na dissertação: o uso das TICs no Curso de Pedagogia: um desafio de repensar o fazer pedagógico e o predomínio dos métodos tradicionais de ensino com o uso das TICs sobre a inovação pedagógica.

Para a identificação dos professores entrevistados, foi escolhido o código $\mathrm{E}$ (entrevistado), mais o número sequencial de 1 a 13, de acordo com a ordem em que foram realizadas as entrevistas.

\section{O uso das TICs no Curso de Pedagogia: um desafio para o fazer pedagógico}

Nesta categoria, explorei com os participantes do estudo a importância das TICs na prática pedagógica, as possíveis dificuldades inerentes ao uso e os saberes necessários para inserir as TICs em sala de aula e nas atividades dos alunos.

A maioria dos entrevistados afirmou que utilizavam as TICs para ministrar aulas e trabalhar com outras atividades do curso, mas demonstraram ter algumas dificuldades. Dos treze professores que participaram do estudo, onze professores relataram que não tiveram contato com as TICs quando fizeram os seus cursos de licenciatura, pois à época da formação, os currículos dos cursos não as contemplavam como recurso pedagógico.

Apesar das dificuldades encontradas e também da resistência de alguns professores para usar as TICs no contexto educacional, grande parte dos professores considerou importante a sua utilização para a formação de professores. O relato do E1 a seguir expressa bem a importância dada pelos entrevistados:

As TICs são essenciais e não tem como fugir disso, nós temos que mudar a realidade de nossas escolas, nós temos que parar de achar que o aluno aprende só escutando e só com giz e quadro, isso é uma coisa que está muito, muito defasada $(\mathrm{E} 1,11$ anos de magistério no ensino superior). 
Neste sentido, a maioria dos professores demonstrou ter sensibilidade da importância do uso das TICs nas aulas e atividades pedagógicas. Para aprofundar essa questão, explorei como os professores do Curso de Pedagogia utilizavam as tecnologias na própria prática pedagógica com os alunos do curso de licenciatura. A maioria relatou que o uso desses recursos está restrito à apresentação de slides, vídeos, músicas e navegação na internet. Isso pode ser observado na fala do E4, que representa a opinião dos demais entrevistados: "Na sala de aula, uso slides, data show, procuro usar muita música, filmes, gosto muito de curtas metragens, porque daí a coisa é dinâmica (E4, 9 anos de magistério no ensino superior)".

Os participantes do estudo argumentaram que quando se trata de recursos tecnológicos mais avançados, sentem dificuldades para trabalhar, como por exemplo, o projetor interativo interligado com vários computadores disponibilizado no laboratório para as atividades docentes. Essa situação fica mais evidente no seguinte relato:

Uso o data show, o notebook, transmissão de vídeos, músicas, isso sim, mas em um equipamento mais elaborado, como no caso da sala com projetor interativo, já não me sinto muito segura de levar uma turma de alunos e chegar lá me expor e não conseguir utilizar. Estou manuseando o equipamento, mas eu não me sinto segura de me expor na frente de uma turma e dizer assim: Ajuda aqui porque a professora não sabe. Então, ainda não me desafiei. (E3, 8 anos de magistério no ensino superior).

O relato acima mostra certo receio dos professores em utilizar recursos tecnológicos mais avançados sem o devido conhecimento. Essa situação acontece porque os professores se sentem inseguros por não dominar a tecnologia, o que Mishra e Koelher (2006), já discutido na revisão de literatura, argumentam quanto o ao uso da tecnologia no contexto pedagógico.

As evidências mostram que os professores estão mais preocupados em aprender a operacionalizar o recurso que em explorar de que maneira vai usá-lo para melhorar e inovar a prática pedagógica. Por se tratar de professores que formam futuros profissionais da educação, perguntei aos participantes do estudo com que frequência eles utilizavam as tecnologias na sua própria prática docente. Dos treze entrevistados, quatro professores relataram que utilizavam com pouca frequência. $\mathrm{O}$ relato a seguir demonstra essa atitude:

Eu usava mais a tecnologia, agora uso menos, porque penso que o aluno se acomoda e se distrai muito se você usa muitas lâminas, mas a tecnologia é uma ferramenta importante que pode ser usada melhorar 
a reflexão e a metodologia dentro da sala de aula. (E10, 12 anos de magistério no ensino superior).

Apesar de os professores do Curso de Pedagogia afirmar que utilizam determinados recursos tecnológicos e que os mesmos são essenciais na formação docente, não são todos os professores que fazem uso frequente das TICs no contexto pedagógico. Além disso, foi possível perceber na fala dos entrevistados que a tecnologia é utilizada de maneira a privilegiar as mesmas formas tradicionais de ensino, ao invés de utilizá-las de maneira inovadora.

No intuito de verificar se essa fragilidade na formação inicial dos professores participantes do estudo influenciava o uso por parte dos alunos, perguntei se os alunos utilizavam recursos tecnológicos na sala de aula e se esse uso era permitido. Os professores responderam que a maioria dos alunos utiliza algum tipo de recurso tecnológico na sala de aula, como por exemplo, celular e notebook, mas não são todos os docentes que concordam com esse uso. Aqueles que não concordam, acreditam que o aluno não consegue focar no que está sendo trabalhado em sala de aula, pois muitas vezes podem estar usando esse recurso para outros fins, alheios ao conteúdo que está sendo abordado pelo professor. No entanto, argumentaram que há a possibilidade de o aluno utilizar a tecnologia para buscar informações sobre o assunto que está sendo ministrado pelo professor. Essa situação foi levantada pelos professores e pode ser observado no relato do entrevistado a seguir, que é representativo dos relatos dos demais participantes do estudo:

Os alunos estão rodeados de tecnologias atraentes, às vezes muito mais do que a própria aula. Às vezes percebemos que eles estão utilizando tecnologias, mas muitas vezes alheio ao foco, ao que se está discutido, mas também muitas vezes o aluno está pesquisando sobre aquilo que está sendo discutido em aula, isso também acontece. (E4, 9 anos de magistério no ensino superior).

Essa percepção do entrevistado acima, de que os alunos estão rodeados de tecnologias, é uma tendência já discutida por alguns autores abordados na revisão de literatura. $\mathrm{O}$ fato de as tecnologias serem utilizadas pelos próprios alunos na universidade implica que os professores não podem ser indiferentes em relação à utilização desses recursos em sala de aula, uma vez que esses alunos já estão inseridos em um mundo tecnológico. 
Outra dificuldade mencionada pelos participantes do estudo foi a respeito do uso das TICs para ministrar aulas com conteúdos de cunho mais teórico. Essa dificuldade foi evidenciada na fala do E10 abaixo,

Certos conteúdos sim, até por questão de conceituação. Então penso que tem certos conteúdos que o melhor é ir ao texto e depois do texto conduzir uma pesquisa na internet. Tenho dificuldades em fazer lâminas porque tem questões teóricas que precisam ser lidas, não só colocadas em tópicos, por isso prefiro que o aluno leia o texto, explicar o texto, explicar as palavras, até porque o vocabulário e o conhecimento conceitual dos nossos alunos são mínimos e nós temos o dever como professor de ajudar as pessoas compreender a questão teórica. Penso que tenho que melhorar, mas prefiro não usar, e tenho dificuldade de usar a tecnologia, não que não poderia, mas para colocar esses elementos teóricos em uma lâmina, até mesmo usando as tecnologias. (E10, 12 anos de magistério no ensino superior).

No relato acima, pode-se perceber que o professor pensa que os recursos tecnológicos não contribuem para trabalhar conteúdos de cunho mais teórico, pois vincula as tecnologias apenas à elaboração de slides para serem apresentados em Power Point e não como um recurso que oferece novas possibilidades para inovar a prática pedagógica, tão necessária nos cursos de licenciatura. As TICs podem ser utilizadas em qualquer disciplina, seja nas ciências exatas ou humanas. O que diferencia a utilização é a maneira, a criatividade e, principalmente o conhecimento do professor de como utilizá-las para tornar o seu conteúdo mais acessível aos alunos. Isso é o que Mishra e Koehler (2006) argumentam quando discutem a importância do Conhecimento Pedagógico Tecnológico do Conteúdo.

Apesar de a maioria dos entrevistados possuírem algumas dificuldades para aliar as TICs com a prática pedagógica, três professores (que ministram tanto disciplinas de formação específica para o magistério quanto de formação geral) demonstraram certa resistência quanto à sua utilização. O relato a seguir é representativo desta atitude:

Não sou apaixonada pelas tecnologias, não é meu chão, tem gente que é apaixonada, eu não, respeito, admiro, mas não é aquilo que flui. Eu gosto de trabalhar com aquilo que flui, tem que vir lá de "dentro". Acho que é importante sim, mas não é só isso, sabe aquela coisa aberta para o que está acontecendo do meu lado, atrás de mim, na minha frente, é isso. (E5, 7 anos de magistério no ensino superior).

Mesmo diante do desenvolvimento acelerado das TICs, a resistência de alguns professores se dá muitas vezes devido aos fatores já citados anteriormente, como 
também em decorrência da descrença das contribuições dos recursos tecnológicos ao processo de ensino-aprendizagem.

Outra questão tratada nesta categoria de análise foi 'a percepção dos professores sobre os saberes necessários para ensinar utilizando as TICs. Quando perguntei aos participantes do estudo qual seria o saber necessário para ensinar utilizando as TICs, dos treze participantes do estudo, apenas três professores enfatizaram que o professor precisa primeiro dominar o conhecimento científico, para conseguir visualizar como a tecnologia pode auxiliar no processo de ensino-aprendizagem, conforme mostra o relato a seguir: "[...] tem que ter conhecimento, se eu sei o conhecimento científico, consigo visualizar no que a tecnologia pode me auxiliar. Por exemplo, não vou conseguir visualizar uma propaganda de TV se eu não tenho conhecimento.” (E1, 11 anos de magistério no ensino superior).

Essa percepção mostra o entendimento dos professores sobre a importância de dominar o conhecimento específico da disciplina para selecionar as tecnologias apropriadas.

O contraponto dessa percepção é que os demais professores entrevistados afirmaram que, para utilizar as TICs na prática pedagógica, basta saber operacionalizar os equipamentos tecnicamente, ou seja, saber ligar, desligar e manuseá-los. O relato a seguir demonstra essa questão: “Acho que é saber manusear, para que eu possa disponibilizar para os meus alunos preciso saber fazer, porque senão eles vão querer entrar em algum lugar e o professor não sabe, daí é perda de tempo, então ter o conhecimento.” (E3, 8 anos de magistério no ensino superior).

É possível afirmar que buscar esse tipo de formação é a preocupação central desses professores para ensinar utilizando as TICs, pois acreditam que ao aprender a manusear os equipamentos, automaticamente saberão utilizar as TICs como recurso para auxiliar no desenvolvimento do processo de ensino-aprendizagem. Talvez essas dificuldades citadas pela maioria dos professores participantes do estudo se devam ao fato de a equipe pedagógica da instituição e os cursos de formação continuada para a utilização das TICs ofertados pela universidade priorizarem mais a operacionalização dos equipamentos que a promoção e o envolvimento em discussões e reflexões a respeito de como aliar a tecnologia, pedagogia e conteúdo.

Em geral, os professores têm noção de que as TICs facilitam o trabalho docente, mas não é garantia de um melhor aprendizado por parte dos alunos. O relato a seguir 
mostra a opinião do E4 e é representativo do que pensam os demais participantes do estudo:

\begin{abstract}
As tecnologias são apoio, mas não é a essência, não dá para colocar a responsabilidade do processo de ensino e aprendizagem nas tecnologias, mas elas fazendo parte da tua prática pedagógica, elas contribuem muito. Então, acho que o grande problema ainda é conceitual. Então, não são elas que determinam o processo de ensino e aprendizagem, mas é com elas que se pode melhorar o ensino e aprendizagem. (E4, 9 anos de magistério no ensino superior).
\end{abstract}

Em síntese, apesar de os professores terem noção que as tecnologias por si só não provocam mudanças no aprendizado dos alunos, eles na própria prática as utilizam apenas tecnicamente, sem considerar as relações existentes entre a tecnologia, o conteúdo e a prática pedagógica. Os docentes precisam mais que simplesmente aprender a usar as TICs tecnicamente, mas também aprender novos métodos e habilidades para integrá-las no contexto pedagógico. Não há uma solução tecnológica que se aplica para cada professor ou curso; um bom ensino utilizando as TICs requer uma compreensão diferenciada das complexas relações entre tecnologia, pedagogia e conteúdo e usar esse entendimento para desenvolver estratégias pedagógicas apropriadas no processo de aprendizagem para a construção do saber. A questão da interseção da tecnologia com o conteúdo e a pedagogia será tratada na categoria a seguir.

\title{
O predomínio dos métodos tradicionais de ensino com o uso das TICs sobre a inovação pedagógica
}

Utilizar as tecnologias para inovar a prática pedagógica exige dos profissionais da educação conhecimento das complexas relações entre três elementos chaves: pedagogia, conteúdo e tecnologia, o que é denominado por Mishra e Koehler (2006) como Conhecimento Tecnológico Pedagógico do Conteúdo (TPCK).

Para tratar essa questão, inicialmente, perguntei aos participantes do estudo se eles consideravam as TICs uma inovação no processo educacional. A maioria dos entrevistados relatou que a tecnologia é considerada uma inovação a partir do momento que a metodologia utilizada pelo professor agrega novas possibilidades de aprendizagem. Isso pode ser observado no relato do entrevistado a seguir:

Se o professor não souber usar a tecnologia, ela não passa de um recurso antigo, como o retroprojetor. Então, o professor tem que saber interagir com a tecnologia, daí sim ela vai ser muito importante para o processo de ensinar e aprender. Como eu estou usando? Direcionar 
para aquilo que estou fazendo, aí ela vai trazer um subsídio importantíssimo. (E2, 9 anos de magistério no ensino superior).

Apesar de os professores demonstrarem alguma sensibilidade para considerar as TICs como inovação no processo educacional, na prática eles utilizam-nas mais para preparar aulas e privilegiar metodologias tradicionais de ensino, para transmitir os conteúdos de suas disciplinas de forma mecânica via o uso de data show, retroprojetor, etc. No entanto, os professores têm noção de que para utilizar as TICs como inovação é necessário promover mudanças nas estratégias de ensino e aprendizagem. Essa noção vai ao encontro dos argumentos de Brito e Purificação (2006), já discutidos na revisão de literatura, em relação ao conceito de inovação com o uso de tecnologias na educação.

Outra questão tratada nas entrevistas foi sobre as vantagens e desvantagens do uso das TICs no contexto educacional. Em relação às vantagens, dos treze participantes do estudo, apenas quatro professores consideraram que a tecnologia permite aos alunos o acesso à informação, ou seja, favorece a autonomia do aluno para buscar conhecimento. Os relatos do E1 e do E4 representam a opinião desses quatro entrevistados em relação às vantagens das TICs na educação.

Eu vejo assim, que hoje o aluno tem uma biblioteca ambulante, onde ele quiser acessar informação ele pode, não precisa ir para lugar nenhum, onde ele estiver consegue ter acesso à informação. Então, digo assim para os alunos: "não aprende quem não quer". Se você teve uma aula de Física e você não entendeu aquele conteúdo, através da tecnologia o aluno pode buscar mais informação, como por exemplo, baixar um vídeo sobre o assunto, enfim tem aquela aula toda de novo, de uma maneira diferente [...]. (E1, 11 anos de magistério no ensino superior).

Acho que favorece a autonomia do aluno, por exemplo, uma pesquisa na internet, isso faz com que o próprio aluno vá em busca de informações, por exemplo, a internet é uma ferramenta. Então isso facilita que o aluno próprio desenvolva a sua autonomia em relação à construção do conhecimento. (E4, 9 anos de magistério no ensino superior).

Os relatos dos professores evidenciam a utilização das tecnologias como ferramentas na busca de informação sobre determinado conteúdo/assunto. Em nenhum momento os professores mencionaram estratégias de ensino com as tecnologias integradas com o conteúdo para promover a aprendizagem do aluno. A maioria dos professores não destacou nenhuma vantagem concreta e específica do uso das TICs nas estratégias e atividades relacionadas ao ensino no curso de Pedagogia. Isso pode ser observado na fala do E11 que expressa a opinião dos demais: "A vantagem encontra-se 
na metodologia do professor, isto é, na maneira que o professor vai utilizar. Se ele não tem uma boa metodologia, a tecnologia não vai fazer diferença." (E11, 22 anos de magistério no ensino superior).

Os professores demonstraram uma visão reducionista em relação ao uso da tecnologia no contexto pedagógico, pois argumentaram que vai depender da metodologia utilizada pelo professor, sem destacar nenhuma atividade mediada pelas TICs. Pode-se constatar, a partir disso, que os professores ainda não utilizam as tecnologias para promover novas perspectivas de aprendizagem capazes de auxiliar os alunos na construção do conhecimento.

Por outro lado, também perguntei aos professores sobre as possíveis desvantagens do uso das tecnologias no curso de pedagogia. Dos treze entrevistados, somente dois professores mencionaram exemplos de desvantagens do uso da tecnologia, conforme pode ser observado nas falas de E1 e E6:

Essa questão já é velha, a geração "copia e cola", ou seja, copiar e colar. A gente tem esse problema aqui na universidade, de o aluno trazer um material simplesmente retirado da internet, que muitas vezes não tira nem aqueles links, copiaram tal e qual [...]. (E1, 11 anos de magistério no ensino superior).

No ensino de artes tem uma desvantagem, a tecnologia gera um ambiente muito limpo, limpo no sentido que não tem barro, não tem areia, não tem massa e, no ensino de arte precisa muito disso. (E6, 10 anos de magistério no ensino superior).

Nos relatos acima, duas questões podem ser observadas: a possibilidade de o aluno adquirir informações prontas e transferi-las para suas tarefas educacionais, sem que essas sejam analisadas e contextualizadas e a limitação do uso da tecnologia a determinadas situações de aprendizagem, pois o contato do aluno com determinados materiais é necessário, como no caso do ensino de artes, mencionado pelo E6, o que no caso pode ser caracterizado como uma desvantagem pontual, específica de uma determinada atividade, mas isso não significa que o uso de tecnologias em outras propostas educacionais referente ao ensino de artes não seja possível. Os professores, por exemplo, podem usar as tecnologias para facilitar e ampliar o campo de pesquisa em artes, o acesso à biografia dos artistas, as coleções, as manifestações artísticas, etc. A integração da arte com as TICs, bem como outras áreas do conhecimento, proporciona novas possibilidades para o ensino, tornando-se importantes recursos no processo de aprendizagem. 
Para reconhecer e ampliar as potencialidades do uso das TICs na educação é fundamental que o profissional da educação repense e compreenda as complexas relações entre tecnologia, conteúdo e pedagogia para aprimorar seu trabalho pedagógico, proporcionando situações de aprendizagem inovadoras, pois diante de um cenário cada vez mais tecnológico, a presença de profissionais qualificados se torna requisito para exercer a profissão.

No entanto, novamente grande parte dos professores não destacou especificamente nenhuma desvantagem do uso da tecnologia nas atividades pedagógicas. O relato do E13 mostra a forma ampla como ele abordou esse assunto, e representa as demais opiniões dos participantes do estudo:

Talvez uma desvantagem seja a de que se o professor não sabe usar a tecnologia só vai complicar a aula. Então, precisa ter uma compreensão dos estudantes, do próprio professor, precisa ter uma adaptação da escola para que seja bem dinamizado [...]. (E13, 9 anos de magistério no ensino superior).

A partir dos relatos dos participantes do estudo, pôde-se perceber a fragilidade dos argumentos para tratar das vantagens e desvantagens do uso das tecnologias em determinadas atividades pedagógicas. Isso talvez se dê pelo fato de que os professores do Curso de Pedagogia não usam e nem exploram as possibilidades e as limitações das TICs no ensino, uma vez que foi possível perceber ao longo das entrevistas que as tecnologias são utilizadas apenas em seu aspecto técnico.

Em síntese, a partir da análise desta categoria foi possível perceber que embora os professores do Curso de Pedagogia não utilizem a tecnologia para inovar a ação pedagógica, eles têm noção de que a inovação baseia-se em atitudes, esforço e uma profunda compreensão de como aliar a tecnologia com a pedagogia e que o avanço tecnológico em várias áreas sociais, econômicas e na área educacional implica em um processo de formação que prepare os futuros profissionais em Pedagogia para lidar com essas questões. Neste sentido, é necessário que o corpo docente repense e avalie as vantagens, desvantagens, o significado e os benefícios que as TICs podem trazer para o ato de ensinar e para a aprendizagem dos alunos, futuros professores.

\section{Discussão e conclusões}

As evidências levantadas nas categorias discutidas nesse artigo mostraram que as tecnologias ainda são utilizadas para práticas tradicionais de transmissão de 
informação, privilegiando assim os métodos tradicionais de ensino. Os professores utilizam as tecnologias mais para preparar aulas que para promover situações de aprendizagem inovadoras. A instituição de ensino necessita de professores que possam ir além do uso das tecnologias para privilegiar as estratégias tradicionais de ensino, e para isto, torna-se imprescindível preparar os professores para usar as TICs pedagogicamente na formação do cidadão, uma vez que saber usar tecnicamente a tecnologia não significa saber ensinar com ela.

Os professores dominam o conhecimento pedagógico do conteúdo de suas disciplinas, mas ainda estão em processo de aprendizagem para utilizar pedagogicamente as TICs no ensino de modo a propiciar melhorias para a aprendizagem do aluno. Esta situação reforça o que Mishra e Koehller (2006) argumentam em relação ao que denominam de Conhecimento Pedagógico Tecnológico do Conteúdo, ou seja, uma nova forma de aliar a tecnologia ao ensino, superando as diferenças entre conteúdo, pedagogia e tecnologia.

Não há uma solução tecnológica que se aplica para cada professor, cada curso, ou para cada ponto de vista do ensino. Esse processo requer o desenvolvimento de uma compreensão diferenciada das complexas relações entre o conhecimento tecnológico, científico e pedagógico e usar esse entendimento para desenvolver estratégias de ensino apropriadas. Para uma integração produtiva da tecnologia na educação é fundamental considerar esses três elementos-chaves não isoladamente, mas sim dentro de suas complexas relações.

Também é importante no processo de integração das TICs na mediação pedagógica, planejar seminários, oficinas a respeito de como usar as tecnologias nas propostas pedagógicas, para que tanto os alunos quanto os professores compreendam a importância e a diferença que esses recursos podem trazer para o contexto educacional e os benefícios que podem proporcionar em relação ao processo educacional.

O profissional da educação precisa estar atento a como e quais as tecnologias podem ser utilizadas para proporcionar situações de aprendizagem inovadoras, e mesmo que possuam algumas dificuldades de operacionalização técnica, os professores necessitam estar atualizados em relação aos recursos tecnológicos mais recentes, como por exemplo, lousa digital, projetores multimídia, computadores, dispositivos móveis, softwares, etc., e explorar as características que estes recursos oferecem na construção de estratégias pedagógicas que favoreçam a construção do conhecimento. Para que o professor compreenda as potencialidades das TICs no contexto educacional é 
fundamental que o conhecimento técnico e pedagógico caminhem juntos na prática docente.

Os professores precisam compreender as características desses recursos e suas melhores formas de utilização no trabalho pedagógico, pois o uso inadequado das TICs pode comprometer o bom ensino. As tecnologias são recursos que podem auxiliar a inovação pedagógica, tanto para os professores que ministram aulas nos cursos de licenciatura em Pedagogia quanto para os alunos, ajudando-os a perceber a sua importância e as várias possibilidades que oferecem para a futura prática profissional.

Preparar os professores para que possam integrar de forma eficaz as TICs contribui para a inovação pedagógica, e esse equilíbrio entre a preparação teórica e prática deve se estender ao longo da carreira docente. Contudo, as TICs devem ser mais bem trabalhadas na formação inicial dos futuros professores para que os alunos e futuros pedagogos aprendam a utilizá-las de maneira que contribua para a construção do conhecimento, ou seja, aliando a tecnologia com o conteúdo e a prática pedagógica.

\title{
INFORMATION AND COMUNICATION TECHNOLOGY AS A PEDAGOGICAL MEDIATION IN THE PEDAGOGY COURSE
}

\begin{abstract}
This article presents part of the results of a Master's thesis held in the Postgraduate Program in Technology at UTFPR, whose objective was to analyze how teachers in a undergraduate course in Pedagogy in a private University at Rio Grande do Sul State - Brazil used information and comunication technologies (ICT) in their teaching practices for training future teachers. The literature review for the study was drawn from several national and international authors. For this article a cut in the literature was done by addressing specifically the importance of using ICT for teacher training and pedagogical innovation. The research approach was. The sample consisted of thirteen teachers. The technique used to data collect the data was the semi-structured interview. For the purpose of this article will be presented just two of the categories discussed in the dissertation. The main results show that ICTs are used to transmit information and not as a resource to assist in the development of teaching-learning process and most of the teachers interviewed have difficulty using technological resources in their teaching practices.
\end{abstract}

KEYWORDS: Education. Information and comunication technology. Learning. Pedagogical mediation. Pedagogical innovation. 


\section{REFERÊNCIAS}

BEHRENS, M. A. Projetos de aprendizagem colaborativa num paradigma emergente. In: MORAN, J. M.; MASETTO, M.; BEHRENS, M. A. Novas tecnologias e mediação pedagógica. Campinas: Papirus, 2000. p.67-132.

BOGDAN, R.; BIKLEN, S. Investigação qualitativa em educação: uma introdução à teoria e aos métodos. Portugal: Porto Editora, 1994.

BRITO, G. S.; PURIFICAÇÃO, I. Educação e novas tecnologias: um re-pensar. Curitiba: IBPEX, 2006.

CARBONELL, J. A aventura de inovar: a mudança na escola. 2.ed. Porto Alegre: ARTMED, 2002.

GLASER, B. G.; STRAUSS, A. L. The discovery of grounded theory. Chicago: Aldine, 1967.

HAYDT, R. C. C. Curso de didática geral. São Paulo: Ática, 2003.

MASETTO, M. T. Inovação na aula universitária: espaço de pesquisa, construção de conhecimento interdisciplinar, espaço de aprendizagem e tecnologias de comunicação. Perspectiva, Florianópolis, v.29, p.597-620, 2011.

MISHRA, P.; KOEHLER, M. J. Technological pedagogical content knowledge: a framework for teacher knowledge. Teachers College Record, New York, v.108, n.6, p.1017-1054, jun. 2006.

MOREIRA, H.; CALEFFE, L. G. Metodologia da pesquisa para professor pesquisador. Rio de Janeiro: DP\&A, 2006.

SHULMAN, L. S. Those who understand: knowledge growth in teaching. Educational Researcher, Washington, v.15, n.2, p.4-14, 1986.

VASCONCELOS, M. L. M. C. A formação do professor do ensino superior. Niterói: Intertexto, 2009. 